\title{
Éliane Viennot, Marguerite de Valois. «La reine Margot»
}

\section{Dario Cecchetti}

\section{(2) OpenEdition}

1 Journals

\section{Edizione digitale}

URL: http://journals.openedition.org/studifrancesi/27488

DOI: 10.4000/studifrancesi.27488

ISSN: 2421-5856

\section{Editore}

Rosenberg \& Sellier

\section{Edizione cartacea}

Data di pubblicazione: 31 décembre 2006

Paginazione: 595-596

ISSN: 0039-2944

\section{Notizia bibliografica digitale}

Dario Cecchetti, «Éliane Viennot, Marguerite de Valois. «La reine Margot»», Studi Francesi [Online], 150 (L | III) | 2006, online dal 30 novembre 2015, consultato il 08 novembre 2020. URL : http:// journals.openedition.org/studifrancesi/27488; DOI : https://doi.org/10.4000/studifrancesi.27488

Questo documento è stato generato automaticamente il 8 novembre 2020.

\section{(c) $(1) \&$}

Studi Francesi è distribuita con Licenza Creative Commons Attribuzione - Non commerciale - Non opere derivate 4.0 Internazionale. 


\title{
Éliane Viennot, Marguerite de Valois. «L reine Margot»
}

\author{
Dario Cecchetti
}

\section{NOTIZIA}

ÉLIANE VIENNOT, Marguerite de Valois. «La reine Margot», Paris, Perrin («Collection Tempus», 109), 2005, pp. 660.

1 Marguerite de Valois, la reine Margot, figlia di Caterina de Medici, sorella di Carlo IX, moglie del futuro Enrico IV, protagonista attiva della vita politica durante le guerre di religione dopo la Saint- Barthélemy, memorialista colta e polemista brillante, appartiene all'immaginario collettivo soprattutto per le rappresentazioni letterarie e romanzesche: da Dumas (ma anche da Stendhal) fino ai feuilletons cinematografici contemporanei (magari pretenziosi, come il film di Patrice Chéreau, del 1994). Éliane Viennot, in un denso lavoro (pubblicato nel 1995 presso Fayard, ristampato ora con una Postface di aggiornamento, pp. 525-536), offre una solida biografia della regina Valois, servendosi degli scritti stessi di Marguerite e degli studi più aggiornati sul periodo che va dalle guerre di religione al regno di Enrico IV. Pur attenta a ricostruire le vicende personali e sentimentali della regina che offriranno materia alle fantasie romanzesche, l'A. traccia un quadro preciso della carriera 'politica' di Marguerite: l'attività diplomatica, l'alleanza con i Malcontents, il supporto offerto ai Bourbons. Ma il volume, che nella prima parte (Histoire d'une femme, pp. 19-304) ricostruisce la biografia vera e propria, nella seconda (Histoire d'un mythe, pp. 307-536) confronta i dati biografici con la loro reinterpretazione (o falsificazione) polemica e letteraria, reinterpretazione che troverà un radicamento tale da costituire un mito dotato di un immaginario ancor oggi funzionante a livello collettivo. Alcuni degli episodi che alimenteranno quella tradizione culminante nel romanzo di Dumas (la regina dedita a passioni sfrenate e a tragici amori) sono inventati già tra la fine del Cinquecento e l'inizio del Seicento (utile è l'accurata, e riassuntiva, cronologia della 'leggenda': pp. 549-551). Ma è l'Ottocento a creare gli elementi del moderno immaginario romanzesco. Senza dubbio questa 
ricostruzione - esemplare - del mito della reine Margot è interessante non solo per quanto concerne la creazione di un personaggio della fantasia collettiva, ma anche come indagine della ricostruzione mitica di un'epoca storica - il tardo Rinascimento che coinvolge un gusto letterario e artistico e svela in quale misura prospettive di lettura 'colta' della storia cinquecentesca, come quelle di Michelet o di Burckhardt, siano grandemente influenzate dalla mitologia romanzesca. 